\title{
Stabilization of nanosized titanium dioxide by cyclodextrin polymers and its photocatalytic effect on the degradation of wastewater pollutants
}

\author{
Tamás Zoltán Agócs ${ }^{1,2}$, István Puskás ${ }^{1}$, Erzsébet Varga ${ }^{1}$, Mónika Molnár ${ }^{2}$ \\ and Éva Fenyvesi ${ }^{* 1}$
}

\author{
Full Research Paper \\ Address: \\ ${ }^{1}$ CycloLab Cyclodextrin R\&D Laboratory Ltd, Illatos út 7, Budapest, \\ 1097, Hungary and ${ }^{2}$ Department of Applied Biotechnology and Food \\ Science, Budapest University of Technology and Economics, Szent \\ Gellért tér 4, Budapest, 1111, Hungary \\ Email: \\ Éva Fenyvesi* - fenyvesi.e@cyclolab.hu \\ * Corresponding author \\ Keywords: \\ carboxymethyl $\beta$-cyclodextrin polymer; colloid stability; ibuprofen; \\ methylene blue; nanoTiO ${ }_{2}$; synergetic effect; wastewater treatment
}

\author{
Beilstein J. Org. Chem. 2016, 12, 2873-2882. \\ doi:10.3762/bjoc. 12.286 \\ Received: 27 September 2016 \\ Accepted: 19 December 2016 \\ Published: 28 December 2016 \\ This article is part of the Thematic Series "Superstructures with \\ cyclodextrins: Chemistry and applications IV". \\ Guest Editor: G. Wenz
}

(C) 2016 Agócs et al.; licensee Beilstein-Institut. License and terms: see end of document.

\begin{abstract}
Advanced oxidation processes (AOPs) are considered highly competitive water treatment technologies for the removal of organic pollutants. Among AOP techniques, photocatalysis has recently been the most widely studied. Our aims were to investigate how the dispersion of nanosized titanium dioxide $\left(\right.$ nano $\left.\mathrm{TiO}_{2}\right)$ applied in photodegradation-based procedures can be stabilized with cyclodextrins in order to obtain a new, more efficient photocatalyst for the purification of waters polluted by xenobiotics applying UV irradiation. During our work, on the one hand, we studied the behavior and stability of nanoTiO $\mathrm{T}_{2}$ in cyclodextrin solutions. On the other hand, we used various monomer and polymer cyclodextrin derivatives, and assessed the options for nanoTiO $\mathrm{T}_{2}$ stabilization in

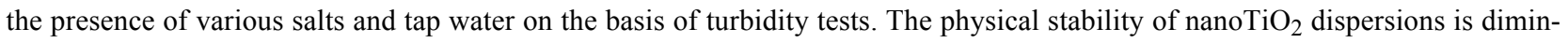
ished in the presence of the salts found in tap water (and occurring also in surface waters and ground water) and they are precipitated immediately. This colloidal instability can be improved by cyclodextrin derivatives. Based on the results of our studies we have selected carboxymethyl $\beta$-cyclodextrin polymer (CMBCD-P) for stabilization of nanoTiO ${ }_{2}$ dispersions. The photocatalytic degradation of methylene blue and ibuprofen as model organic pollutants in various media (distilled water, $\mathrm{NaCl}$ solution and tap water) has been studied using nanoTiO $\mathrm{Ti}_{2}$ as catalyst stabilized by CMBCD-P. CMBCD-P itself showed a catalytic effect on the UV degradation of methylene blue. In addition to enhancing the colloid stability of nanoTiO $\mathrm{CMBCD}_{2} \mathrm{P}$ showed also synergistic effects in catalyzing the photodecomposition process of the dye. On the other hand, ibuprofen as a model pharmaceutical, a pollutant of emerging concern (EP), was protected by CMBCD-P against the photocatalytic degradation showing that inclusion complex formation can result in opposite effects depending on the structure of the host-guest complex.
\end{abstract}




\section{Introduction}

The wastewater purification and reuse are key challenges of our society. Globally $330 \mathrm{~km}^{3} \mathrm{year}^{-1}$ municipal wastewater is produced [1]. According to the European Investment Bank, by 2025,800 million people will be living in regions in shortage of drinking water [2]. The recently recognized harmful xenobiotics (contaminants of emerging concern, such as pharmaceutical residues, personal care products, industrial additives) impose a high risk on the environment and also on human because they usually do not degrade in nature, appear in surface waters and groundwater, and may accumulate in living organisms [3,4]. From time to time, these microcontaminants can also be detected in tap water and may pose a risk for human, too [5]. These microcontaminants are xenobiotics for the microbes used in the secondary treatment (after sedimentation, which is the primary treatment) of wastewater, so these compounds are not efficiently eliminated with the conventional technologies from the effluent. To avoid the contamination of the receiving environment (sea, river, lake, wetlands, ground, etc.) it is essential that efficient and economical treatment procedure(s) are elaborated for the removal of such microcontaminants. Various sorbents containing cyclodextrin (CD) have been developed aiming at the removal of pharmaceutical residues, pesticides and other endocrine disrupting compounds from purified wastewater [6,7]. CDs are cyclic oligosaccharides consisting of $6-8$ glucose units $(\alpha-, \beta$ - and $\gamma-C D)$ primarily used in the pharmaceutical, cosmetic and household chemical industry [8]. They form non-covalent inclusion complexes with a great number of the organic contaminants in soil (petroleum hydrocarbons, polycyclic aromatic hydrocarbons, etc.) and microcontaminants occurring in water (pharmaceutical and cosmetic active agents, pesticides, etc.). The $\mathrm{CD}$ derivatives, which are well soluble in water, such as hydroxypropyl and methylated CDs, can enhance desorption of the contaminants from the soil and are useful in soil remediation technologies (e.g., in situ/ex situ microbial degradation and chemical oxidation of contaminants in soil) $[9,10]$. Immobilizing CDs either by crosslinking or by coupling to the surface of natural or synthetic polymers CD-based sorbents are obtained in the form of beads, nanosponges, microfibers, etc., which are able to remove microcontaminants from purified wastewater [11-17] and can be also used as samplers [12]. Further methods applying CDs for wastewater purification include $\mathrm{CD}$-intensified biodegradation of contaminants [18], and oxidation of micropollutants adsorbed on cyclodextrin polymer (CDP) using $\mathrm{KMnO}_{4}$ [19]

Advanced oxidation processes (AOPs) based on in situ generation of highly reactive species can mineralize organic contaminants into relatively harmless compounds. Research activities have been recently focused on photocatalysis belonging to these AOP techniques [20-24]. The photodegradation is a technology utilizing the energy of light for decomposition of the contaminants. CD can catalyse or inhibit the photodecomposition of a compound depending on the position of the light-sensitive bonds of the included compound. For instance, photodegradation of bisphenol A was enhanced in aqueous solutions containing $\beta-C D$ [25], while the photodecomposition of pesticides of similar structure (parathion and paraoxon) was inhibited or catalyzed, respectively, by $\beta$-CD [26]. The complex formation can either protect the drug from the effect of light or accelerate the decomposition [27,28].

Recently, various photocatalysts modified by CDs have been described. For instance, reduced graphene oxide/ $\beta-\mathrm{CD} /$ titanium dioxide showed enhanced removal of phenol and $\mathrm{Cr}$ (VI) [29], graphene nanosheets with self-assembled nanolayer of $\mathrm{TiO}_{2}$ stabilized by $\beta-C D$ resulted in improved photodegradation of methylene blue [24], and CD-functionalized $\mathrm{Fe}_{3} \mathrm{O}_{4} / \mathrm{TiO}_{2}$ was efficient catalyst in photodecomposition of endocrine disrupting compounds, such as bisphenol A and dibutyl phthalate [30].

Producing strong oxidizing radicals (hydroxyl and superoxide radical ions) titanium dioxide is a widely used catalyst for photodecomposition of various organic pollutants [31]. The photocatalytic reactions take place on the surface of the catalyst on the effect of solar light or of artificial UV light irradiation. In the practice, $\mathrm{TiO}_{2}$ is immobilized on a surface, e.g., glass wool mats or ceramic plates and a thin layer of waste water is treated by solar light to achieve the decomposition of the organic pollutants [32]. Another way of enhancing the surface is the application of nanoparticles $\left(\right.$ nanoTiO $\left.{ }_{2}\right)$. Such nanosized particles can readily aggregate forming larger agglomerates of reduced surface and reduced catalytic activity. The aggregation is a slow process in distilled water, but happens instantly in the presence of salts, e.g., in tap water, surface waters and waste waters. $\beta-\mathrm{CD}$ can be used for stabilization of colloidal $\mathrm{TiO}_{2}$ systems [33] - at least in distilled water - as it is adsorbed on the surface of the nanoparticles (with its wider secondary side, Figure 1) [34]. In addition to the improvement of the colloidal stability, also the efficiency of the photocatalytic performance of nanoTiO ${ }_{2}$ particles can be enhanced by adsorption of $\beta-C D$. The latter plays electron-donating and hole-capturing roles when linked to nanoTiO 2 colloids leading to restriction of charge-hole recombination [35]. The efficiency is further improved by keeping the ligands close to the surface of nanoTiO via inclusion complexation. In other studies the presence of CDs caused a delay in the photocatalytic degradation of toluene [36].

Although several operating parameters (concentration of pollutants, $\mathrm{pH}$, irradiation time etc.) have already been investigated 

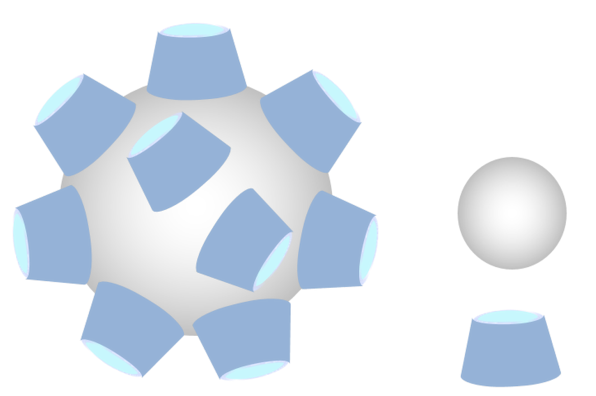

nano $\mathrm{TiO}_{2}$

CD

Figure 1: Adsorption of $\beta-C D$ on the surface of nanoTiO 2 [37]

most of the experiments published so far were performed only in distilled water [23,38-40]. In the present work we aimed at finding a cyclodextrin derivative which effectively protects nanoTiO $\mathrm{T}_{2}$ in aqueous media against the precipitating effect of different salts in tap water. We used turbidity and light scattering measurements for studying the aggregation behavior of nanoTiO ${ }_{2}$. In a second step, the photocatalytic properties of the stabilized nanoTiO ${ }_{2}$ dispersions have been studied for degradation of some model organic pollutants (methylene blue and ibuprofen) under UV-A light irradiation.

\section{Results and Discussion Selection of the $C D$ derivative for stabilizing nanoTiO 2 dispersions}

In aqueous dispersions, in the presence of salts the nanoparticles of $\mathrm{TiO}_{2}$ start to aggregate and form larger particles enhancing the turbidity of dispersion. The turbidity (the haziness of the dispersion caused by particles invisible for the naked eye) was measured to monitor the aggregation of the particles of nanoTiO ${ }_{2}$. Various monomer and polymer CD derivatives were studied how they influence the stability of nanoTiO ${ }_{2}$ in the presence of $\mathrm{NaCl}(0.1 \%)$ by recording the turbidity. We used neutral and charged $\mathrm{CD}$ derivatives, such as non-ionic 2-hydroxypropyl- $\beta$-cyclodextrin monomer (M) and polymer (P) (HPBCD$\mathrm{M} / \mathrm{P})$, anionic carboxymethyl- $\beta$-cyclodextrin monomer and polymer (CMBCD-M/P) and quaternary ammonium $\beta$-cyclodextrin polymer (QABCD-P) in a concentration of $1 \%$ $(50 \mathrm{mg} / 5 \mathrm{~mL})$. The polymers were prepared by crosslinking the proper monomers with epichlorohydrin and contained 4-200 $\beta$-CD units. None of the monomers could hinder the aggrega- tion of nanoTiO 2 in $0.1 \% \mathrm{NaCl}$ solution while the polymers showed stabilizing effect (Table 1).

The effects of the polymer concentration ( $1 \%$ and $5 \%)$ and its average molecular weight ( $90 \mathrm{kDa}, 200 \mathrm{kDa}, 300 \mathrm{kDa})$ on the colloidal stability of the nanoTiO ${ }_{2}$ dispersion were also studied using the neutral HPBCD-P. It was clearly shown that the stabilization effect was not influenced by the average molecular weight and there was no remarkable difference between the samples with $1 \%$ and $5 \%$ polymer concentration (the turbidity in salt solution changed to $102-107 \%$ and $102-105 \%$ related to the initial after $120 \mathrm{~min}$, respectively. Results are not presented here.)

After diluting nanoTiO $\mathrm{Ti}_{2}$ dispersions with tap water immediate precipitation was observed. Among the $\mathrm{CD}$ polymers studied the QABCD-P could not hinder this precipitation, the HPBCD$P$ slowed down the precipitation process, while in the presence of CMBCD-P no precipitation occurred in 120 min (Figure 2).

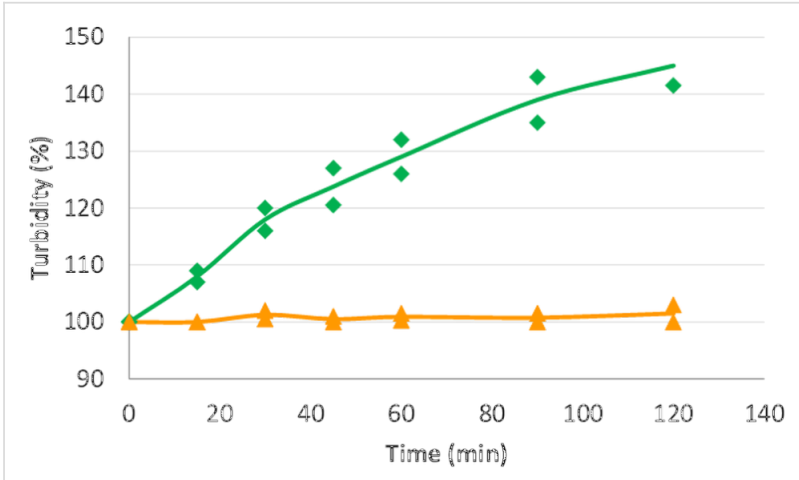

Figure 2: Turbidity of nanoTiO $\mathrm{Tis}_{2}$ dispersion $(0.02 \%)$ in the presence of $1 \%$ HPBCD-P (green diamond) and 1\% CMBCD-P (yellow triangle) in tap water.

As the lowest enhancement in turbidity both in $\mathrm{NaCl}$ solution and in tap water was obtained with the polymer of the carboxymethyl $\beta$-CD derivative (CMBCD-P), this material was selected for further studies.

The colloidal stability of nanoTiO 2 dispersions in various salt solutions was examined in the presence of some selected ions typical in tap water. Without the CD polymer additive the

Table 1: Turbidity of $0.02 \%$ nano $\mathrm{TiO}_{2}$ dispersions in the presence of $1 \% \mathrm{CD}$ polymers in distilled water and in $0.1 \% \mathrm{NaCl}$ solution at 120 min related to the initial turbidity $(100 \%)$

\begin{tabular}{lcccc} 
& No CD & HPBCD-P & CMBCD-P & QABCD-P \\
\hline Distilled water & $100 \pm 2 \%$ & $104 \pm 2 \%$ & $101 \pm 2 \%$ & $101 \pm 2 \%$ \\
$0.1 \% \mathrm{NaCl}$ solution & $209 \pm 5 \%$ & $107 \pm 2 \%$ & $101 \pm 2 \%$ & $103 \pm 2 \%$
\end{tabular}


nanoTiO ${ }_{2}$ was immediately precipitated in the solution of $0.1 \%$ $\mathrm{Na}_{2} \mathrm{SO}_{4}$, and a fast enhancement of the turbidity was observed in the presence of the other salts: $\mathrm{Ca} / \mathrm{MgCl}_{2}$ and $\mathrm{Na}_{2} \mathrm{CO}_{3}$. The dispersion was stable at as low concentration as $1 \%$ CMBCD-P and the turbidity remained $<105 \%$ within 120 min of observation (Table 2).

The stabilizing effect of the CD-based polymers especially of CMBCD-P can be attributed to steric effects caused by the adsorption of the polymer on the surface of nanoTiO 2 particles. It forms a layer, which inhibits their aggregation. The negative charge contributes to the stabilizing effect by i) electrostatic attraction of the sorbed layer to the positively charged holes on the nano $\mathrm{TiO}_{2}$ particles and ii) repulsion between the particles covered by the polymer layer.

\section{Aggregation studies}

Based on particle size measurements the aggregation behavior of nano $\mathrm{TiO}_{2}$ in the presence and absence of polymer was compared in different media. We studied the effect of $\mathrm{NaCl}$ and tap water.
The applied nanoTiO 2 consists of crystallites of $10-20 \mathrm{~nm}$ diameter as evidenced by scanning electron micrographs provided by Evonik [41]. However, in aqueous dispersion prepared in our laboratory, these nanocrystallites form - still relatively small - aggregates having a mean size of 50-60 nm (Figure 3 and Figure 4, red curves).

The particle size distribution of nanoTiO ${ }_{2}$ in the absence of destabilizing ions is relatively narrow and nearly harmonic (mean aggregate size: $55 \mathrm{~nm}$ ) as shown in Figure 3 and Figure 4 . In the presence of $0.1 \% \mathrm{NaCl}$, the loss of stability is indicated by the increase of the mean size to $3150 \mathrm{~nm}$ two hours after addition. When CMBCD-P is adsorbed onto the nanoTiO only partial aggregation was observed. A bimodal distribution was obtained. The smaller sized fraction $(71 \%$ of the total sample) had a mean size of $90 \mathrm{~nm}$, while the larger sized fraction ( $29 \%$ of the total sample) had a mean size of $1060 \mathrm{~nm}$ two hours after addition. As the photocatalytic degradation experiments were carried out for $60 \mathrm{~min}$ even this partial stabilizing effect of the polymer seemed to be enough for keeping the catalytic efficiency of the nanocatalyst.

Table 2: The effect of salts $(0.1 \%)$ on the turbidity of nanoTiO 2 aqueous dispersions $(0.02 \%)$ in the presence and absence of $C M B C D-P(1 \%)^{a}$.

\begin{tabular}{|c|c|c|c|c|c|}
\hline & \multicolumn{5}{|c|}{ Relative turbidity (\%) } \\
\hline & $\mathrm{NaCl}$ & $\mathrm{CaCl}_{2}$ & $\mathrm{MgCl}_{2}$ & $\mathrm{Na}_{2} \mathrm{CO}_{3}$ & $\mathrm{Na}_{2} \mathrm{SO}_{4}$ \\
\hline No CD & $209 \%$ & $>200 \%$ * & $>200 \% * *$ & $220 \%$ * & $\begin{array}{l}\text { immediate } \\
\text { precipitation }\end{array}$ \\
\hline CMBCD-P & $100.1 \%$ & $100.2 \%$ & $100.1 \%$ & $100.4 \%$ & $100.0 \%$ \\
\hline
\end{tabular}

aTurbidity after $120 \mathrm{~min}\left({ }^{*} 20 \mathrm{~min},{ }^{* *} 60 \mathrm{~min}\right)$ related to the initial value.

Size Distribution by Volume

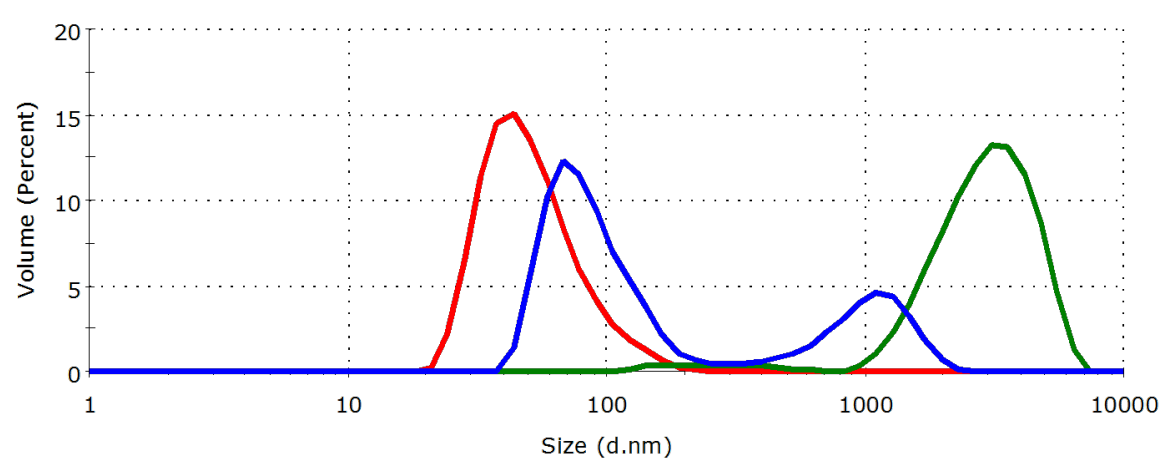

Figure 3: Aggregation effect of $0.1 \% \mathrm{NaCl}$ on $0.02 \%$ nanoTiO $\mathrm{O}_{2}$ dispersion in the absence (green curve) and presence of $\mathrm{CMBCD}-\mathrm{P}$ polymer (blue curve). The red curve shows the particle size distribution in the absence of destabilizing ions. 


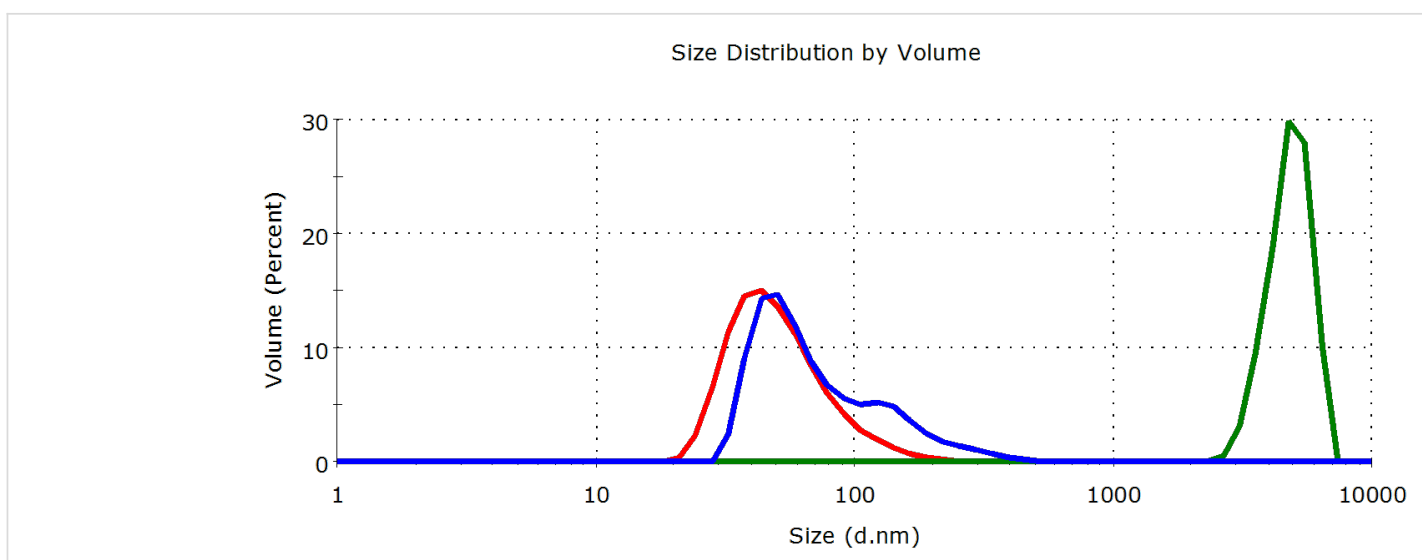

Figure 4: Aggregation effect of tap water on $0.02 \%$ nanoTiO2 dispersion in the absence (green curve) and presence of CMBCD-P polymer (blue curve). The red curve shows the particle size distribution in the absence of destabilizing ions.

In tap water, the stability of nano $\mathrm{TiO}_{2}$ is similarly diminished as observed for $0.1 \% \mathrm{NaCl}$. The mean particle size increased to $4880 \mathrm{~nm}$. It is notable that CMBCD-P proved to be more effective in this medium than in $0.1 \% \mathrm{NaCl}$ solution. The initial particle size distribution of nanoTiO 2 was nearly preserved, the mean size increased only to $59 \mathrm{~nm}$, however, the distribution profile became slightly wider and a shoulder peak at $168 \mathrm{~nm}$ appeared on the curve.

\section{Photocatalytic effect of the CMBCD-P stabi- lized nanoTiO 2 dispersions}

The photocatalytic effect of nanoTiO $\mathrm{Ti}_{2}$ on the decomposition of two model contaminants: a dye (methylene blue, MB) and a drug (ibuprofen, IBR) was studied in various media (distilled water, $\mathrm{NaCl}$ solution and tap water) in the presence and absence of the polymer. The concentrations of the model compounds were measured as a function of time and the half-life time values were calculated to characterize the reaction rate of the degradation. For comparison, the decomposition of the model compounds was measured also without any additives and in the presence of CMBCD-P only. The results for MB are summarized in Figure 5 and Table 3.

Interestingly, without catalyst MB was decomposed faster in tap water than in distilled water most probably due to the small concentration of iron present. Fe(III) and organic carboxylic acid, which coexist in natural environments, can set up a photoFenton system with $\mathrm{H}_{2} \mathrm{O}_{2}$ produced in situ generating $\mathrm{OH}$ radicals of high oxidizing capacity $[42,43]$. Nitrate could also produce $\mathrm{OH}$ radicals when absorbing UV light, but the low concentration of nitrate in tap water can insignificantly contribute to enhancing photodegradation.

The polymer itself showed some catalytic effect: the rate of degradation of MB was slightly increased in all the three media
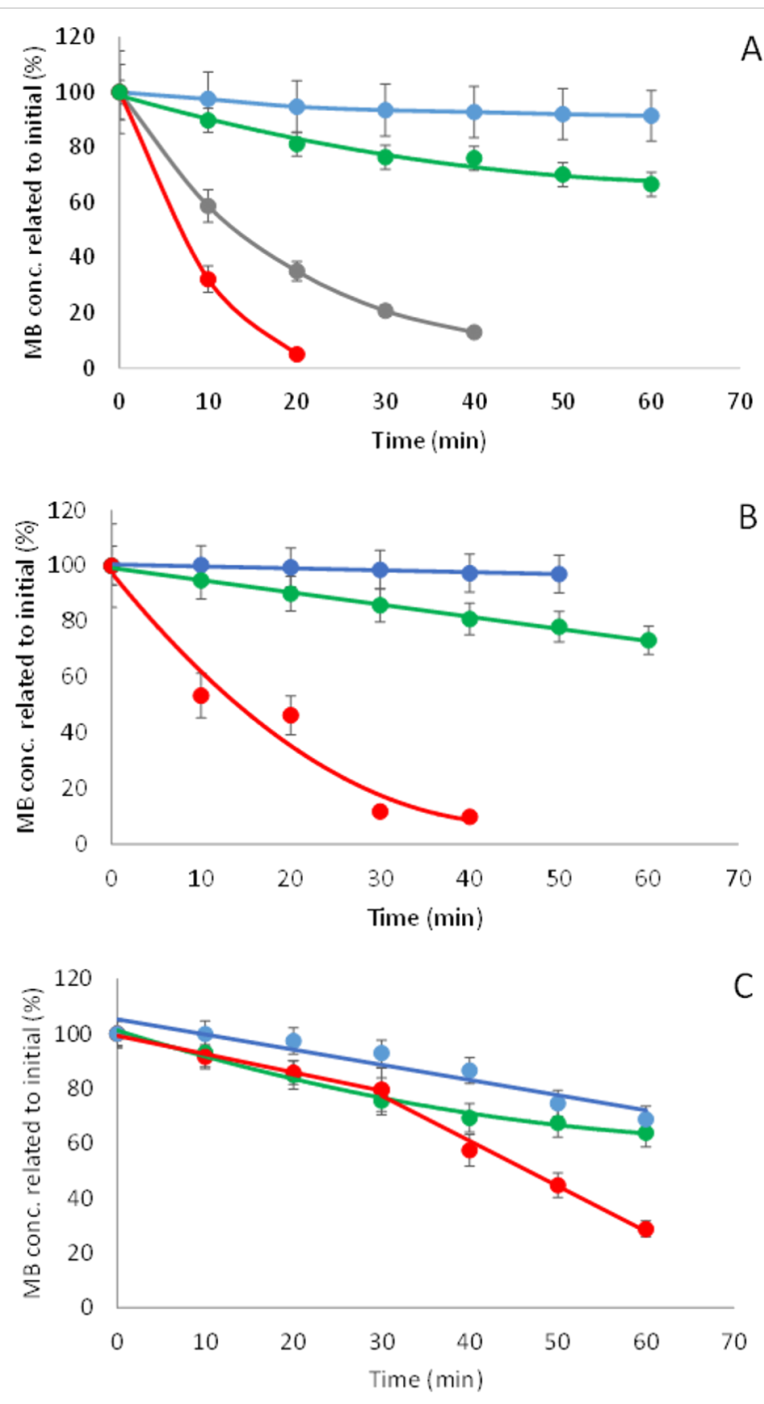

Figure 5: Photodegradation of $\mathrm{MB}$ in aqueous solutions: distilled water (A), $0.1 \% \mathrm{NaCl}$ solution (B) and tap water (C) examining the dye itself (blue), in the presence of $1 \%$ CMBCD-P (green), of $0.02 \%$ nanoTiO 2 (grey) and $0.02 \%$ nanoTiO 2 stabilized by $1 \%$ CMBCD-P (red). 
Table 3: Half-life time $(\mathrm{min})$ of photodegradation of $\mathrm{MB}$ in aqueous solutions in the absence and presence of $\mathrm{CMBCD}-\mathrm{P}(1 \%)$, nanoTiO $2(0.02 \%)$ and nanoTiO $2(0.02 \%)$ stabilized by CMBCD-P $(1 \%)$.

$\begin{array}{lllll}\text { Medium } & \mathrm{MB} & \mathrm{MB}+\mathrm{CMBCD}-\mathrm{P} & \mathrm{MB}+\mathrm{nanoTiO}_{2} & \begin{array}{c}\mathrm{MB}^{2}+\mathrm{nanoTiO}+ \\ \mathrm{CMBCD}-\mathrm{P}\end{array} \\ & & & & 4.6 \pm 0.5 \\ \text { Distilled water } & 495 \pm 45 & 108 \pm 11 & 13.5 \pm 2.5 & 11.3 \pm 1.3 \\ \mathrm{NaCl} \text { solution }(0.1 \%) & 990 \pm 70 & 136 \pm 12 & \text { precipitation } & 94.2 \pm 0.5(\text { phase 1) } \\ \text { Tap water } & 107 \pm 10 & 88.8 \pm 7 & \text { precipitation } & 24.6 \pm 3.6 \text { (phase 2) }\end{array}$

resulting in the shortest half-life time in tap water similarly to the dye alone.

The catalytic effect of nanoTiO 2 itself could be measured only in distilled water, as both in $\mathrm{NaCl}$ solution and in tap water it was precipitated if not stabilized by CMBCD-P. In any media studied the reaction rate followed the order of: no additive $<$ CMBCD-P $<$ nanoTiO $2<$ nanoTiO $2 /$ CMBCD-P.

Applying the nanoTiO 2 stabilized by the polymer synergistic effect was observed in distilled water. $\mathrm{In} \mathrm{NaCl}$ solution the rate of decomposition was lower partly attributed to adsorption of chloride on $\mathrm{TiO}_{2}$ surface. There might be a competition between dyes and anions for the adsorption sites and the anions may modify the superficial properties of $\mathrm{TiO}_{2}$ [44]. The total concentration of inorganic ions in tap water is much lower than $0.1 \%$, therefore this competition for the sorption sites is probably less pronounced even if we take into account that hydrogencarbonate, hydrogenphosphate and sulfate ions hinder the MB adsorption in a higher extent compared to chloride [44].

The nanoTiO 2 stabilized by the polymer showed peculiar behavior in tap water: MB was decomposed in two distinct phases. In the first $30 \mathrm{~min}$ a slow degradation was observed (similar to that observed with the polymer only) and it was followed by fast decomposition (Figure 5 and Table 3). Similar two-stage degradation was observed for the photocatalytic decomposition of pharmaceutical residues, such as carbamazepine and ibuprofen in wastewater with $\mathrm{TiO}_{2}$ catalyst $[42,45]$. It was proved that the natural organic matter (NOM) which are the humic substances present in surface waters and tap water had an initial inhibiting effect: after the decomposition of NOM the drug degradation was enhanced $[42,45]$. The tap water (our test solution) also contained some dissolved organic components (1-2 mg/L) and this would explain our observation.

A different behavior was witnessed in the case of ibuprofen in our experiments. This drug was slowly decomposed in distilled water without any additives (Figure 6 and Table 4) and a slight enhancement in the degradation rate was obtained with nano $\mathrm{TiO}_{2}$. In the presence of the polymer the rate of degradation decreased suggesting that the complex formation of ibuprofen has a protective effect. Using the CMBCD-P-stabilized nano $\mathrm{TiO}_{2}$ as additive hardly any decrease in the drug concentration upon UV irradiation was measured especially in tap water.

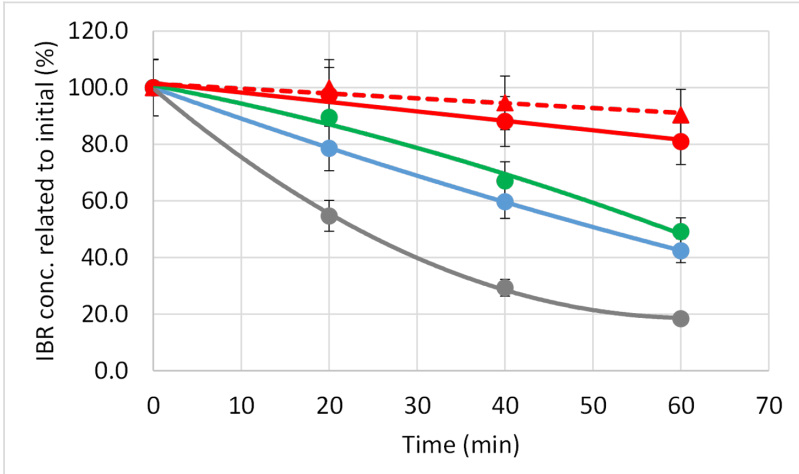

Figure 6: Photodegradation of IBR in distilled water examining the drug itself (blue circle), and in the presence of 1\% CMBCD-P (green circle), of $0.02 \%$ nanoTiO 2 (grey circle), $0.02 \%$ nanoTiO ${ }_{2}$ stabilized by $1 \%$ CMBCD-P (red circle), and $0.02 \%$ nanoTiO $_{2}$ stabilized by $1 \%$ CMBCD-P in tap water (red triangle).

It is well-known that the complexation often has a protective effect on the included guest molecules [8]. Either catalysis or

Table 4: Half life time (min) of photodecomposition of IBR in distilled and tap water

\begin{tabular}{|c|c|c|c|c|}
\hline Medium & IBR & IBR + CMBCD-P & $\mathrm{IBR}+$ nanoTiO $_{2}$ & $\begin{array}{l}\text { IBR + nanoTiO } \\
\text { CMBCD-P }\end{array}$ \\
\hline Distilled water & $31 \pm 13$ & $61 \pm 18$ & $25 \pm 6$ & $201 \pm 56$ \\
\hline Tap water & no data & no data & precipitation & $331 \pm 54$ \\
\hline
\end{tabular}


inhibition of the light-induced cleavage can occur depending on the conformation of the host-guest complex (if the light-sensitive part of the molecule is located within or outside of the cavity), on the complex association constant and on the concentration ratio of the guest to the $\mathrm{CD}$. It was shown that the photodecomposition of $\mathrm{MB}$ was enhanced by stabilizing $\mathrm{Ag} / \mathrm{TiO}_{2}$ nanoparticles with $\beta-\mathrm{CD}$, but applying $\beta-\mathrm{CD}$ in excess the rate of degradation decreased dramatically [46]. The association constant of IBR/ $\beta-C D$ complex falls in the range of $10^{3}-10^{4} \mathrm{M}^{-1}[47,48]$, while that of $\mathrm{MB} / \beta-\mathrm{CD}$ is less than $10^{3} \mathrm{M}^{-1}[49,50]$. According to NMR studies IBR is deeply included into the cavity [51], while MB is too large to be completely shielded by complexation. The too strong association between IBR and the cavities of CMBCD-P can be a possible reason of protection instead of catalytic decomposition in this process. Further experiments are needed to clarify why enhanced protection was observed when the polymer was present together with $\mathrm{TiO}_{2}$.

In order to check if the polymer itself is degraded similarly to the model pollutants as a control experiment, the CMBCD-P solution with and without nano $\mathrm{TiO}_{2}$ was irradiated under identical conditions as the photodegradation of the pollutants. Size exclusion chromatography (HPLC) was used to characterize the composition of the polymer. This method enables to discriminate between the smaller and larger components and to monitor the degradation of the polymer. The chromatograms of the samples before and after irradiation match within the experimental error proving that no significant change in the polymer structure occurred upon UV light irradiation even in the presence of nanoTiO 2 under the applied conditions (irradiation for $1 \mathrm{~h}$ ). Lannoy et al. published the photodegradation of toluene in the presence of nanoTiO ${ }_{2}$ stabilized by native $\beta$-cyclodextrin and its random methylated derivative (BCD and RAMEB, respectively.) [36]. In the first hour $88 \%$ and $97 \%$ of the initial CD concentration was measured by phenolphthalein complexation, respectively, and $34 \%$ and $18 \%$ of these CDs were degraded in
5 hours. These results show that the substituted CDs are of higher stability compared to the unsubstituted one. The CMBCD-P is an epichlorohydrin-crosslinked polymer with the number of substituents/CD of approximately 10 (in RAMEB $\approx 12$ ). Although the conditions of the photodegradation experiments published by Lannoy [36] are different from ours, the $<5 \%$ degradation of CMBCD-P within $1 \mathrm{~h}$ seems to be in agreement with $3 \%$ degradation of RAMEB within the same time period. Further experiments are needed to reveal the fate of CMBCD-P during longer irradiation.

\section{Conclusion}

We have successfully selected a potential stabilizing agent, carboxymethyl $\beta$-cyclodextrin polymer for improving the colloidal stability of nanosized $\mathrm{TiO}_{2}$. Dynamic light scattering measurements proved that the aggregation of $\mathrm{TiO}_{2}$ nanoparticles was hindered by the presence of this polymer additive. Studying its influence on the photocatalytic effect on nanosized $\mathrm{TiO}_{2}$ on one hand a synergistic photocatalytic effect was observed for photodecomposition of the methylene blue in tap water, on the other hand a protective effect of CMBCD-P was observed for the ibuprofen degradation. The efficiency of the CMBCD-P-stabilized nanosized $\mathrm{TiO}_{2}$ photocatalytic system will be studied on further model compounds selected among the emerging pollutants.

\section{Experimental \\ Materials}

Applying the procedure of CycloLab Ltd. Budapest Hungary a dispersion of $9.96 \%$ nanoTiO $\mathrm{Ti}_{2}$ has been prepared from the Degussa-Evonik (Japan) titanium dioxide sample (Aeroxide P90 consisting of anatase $90 \%$ and rutile $10 \%$ with a specific surface area of $90-100 \mathrm{~m}^{2} / \mathrm{g}$ and mean particle size $14 \mathrm{~nm}$ ). This dispersion ( $\mathrm{pH}$ was about 2 ) was diluted to $0.02 \%$ for the experiments. The cyclodextrins characterized by the degree of substitution (DS) in the case of monomers and by the CD content in the case of polymers (Table 5) are all CycloLab's

Table 5: Cyclodextrins used during the experiments.

\begin{tabular}{|c|c|c|c|}
\hline & Abbreviation & Characteristics & $\begin{array}{l}\text { Average molecular } \\
\text { weight }\left(M_{\mathrm{w}}\right)^{\mathrm{a}}\end{array}$ \\
\hline hydroxypropyl- $\beta$-cyclodextrin & HPBCD-M & $\mathrm{DS} \approx 4,2$ & $1.38 \mathrm{kDa}$ \\
\hline $\begin{array}{l}\text { hydroxypropyl- } \beta \text {-cyclodextrin polymer crosslinked with } \\
\text { epichlorohydrin }\end{array}$ & HPBCD-P & CD content: $\approx 65-70 \%$ & $\begin{array}{l}90 \text { kDa; } 200 \text { kDa; } \\
300 \text { kDa }\end{array}$ \\
\hline carboxymethyl- $\beta$-cyclodextrin & CMBCD-M & $\mathrm{DS} \approx 4$ & $1.36 \mathrm{kDa}$ \\
\hline $\begin{array}{l}\text { carboxymethyl- } \beta \text {-cyclodextrin-polymer crosslinked with } \\
\text { epichlorohydrin }\end{array}$ & CMBCD-P & $\begin{array}{l}\text { DS 2-3; CD content: } \\
\approx 65-70 \%\end{array}$ & 33 kDa \\
\hline $\begin{array}{l}\text { quaternary ammonium } \beta \text {-cyclodextrin polymer } \\
\text { crosslinked with epichlorohydrin }\end{array}$ & QABCD-P & $\begin{array}{l}\mathrm{DS} \approx 0.2 \\
\mathrm{CD} \text { content: } \approx 65-70 \%\end{array}$ & $\approx 6 \mathrm{kDa}$ \\
\hline
\end{tabular}

aFor monomers it is calculated, for polymers data were obtained by static light scattering. 
products. The DS and the CD content were determined by NMR as described earlier [52]. The molecular weights were determined by static light scattering as described by Puskás et al. [53]. The salts $\left(\mathrm{NaCl}, \mathrm{CaCl}_{2}, \mathrm{MgCl}_{2}, \mathrm{Na}_{2} \mathrm{CO}_{3}, \mathrm{Na}_{2} \mathrm{SO}_{4}\right)$, $\mathrm{NaOH}$ and the model pollutants (methylene blue, $\mathrm{MB}$ and ibuprofen, IBR) are analytical grade chemicals purchased from Molar (Hungary).

\section{Composition of tap water}

The tap water in the district where the laboratory is located contains the following minerals according to the Budapest Potable Water Analysis [54]: $\mathrm{Cl}^{-} 21 \mathrm{mg} / \mathrm{L}, \mathrm{Na} 11 \mathrm{mg} / \mathrm{L}, \mathrm{Ca}^{2+}$ $60 \mathrm{mg} / \mathrm{L}, \mathrm{SO}_{4}{ }^{2-} 27 \mathrm{mg} / \mathrm{L}, \mathrm{HCO}_{3}{ }^{-} 150 \mathrm{mg} / \mathrm{L}, \mathrm{NO}_{3}{ }^{-} 5 \mathrm{mg} / \mathrm{L}$, orthophosphate $<5 \mathrm{mg} / \mathrm{L}$. The electric conductivity is $480 \mu \mathrm{S} / \mathrm{cm}$ and $\mathrm{pH}$ 7.5. Total organic carbon content (TOC) $1-2 \mathrm{mg} / \mathrm{L}$.

\section{Methods}

\section{Turbidity measurements}

Turbidity of the nanoTiO $\mathrm{Ti}_{2}$ dispersions was measured at $410 \mathrm{~nm}$ by Agilent 8453 spectrophotometer. The samples were measured in glass cuvettes of $1 \mathrm{~cm}$.

\section{Determinations of moisture content}

The moisture content of the CMBCD-P has been determined using a 'Karl Fischer V20' type auto-titration device (Mettler Toledo).

\section{Light scattering measurements}

Determination of average molecular weight by static light scattering: The average molecular weight of the water-soluble polymers has been determined by static light scattering method using a Malvern Zetasizer Nano Series ZS device manufactured by Malvern Instruments Ltd., UK. The analysis was performed as described elsewhere [53].

Particle size analysis by dynamic light scattering: Determination of the particle size distribution of the nanoTiO 2 particles and aggregates was performed by dynamic light scattering method (also known as photon correlation spectroscopy) using a Malvern Zetasizer Nano ZS instrument using a He-Ne laser of $4 \mathrm{~mW}$ power and $633 \mathrm{~nm}$ wavelength and avalanche photodiode detector. Triplicate measurements were carried out for all samples, each averaged of at least 10 runs at $25^{\circ} \mathrm{C}$. The volume size distribution was utilized for aggregate state analysis.

\section{Photodegradation experiments}

The degradation of methylene blue and ibuprofen was studied using an optical bench with medium pressure mercury-vapor lamp of $200 \mathrm{~W}$ (Tunsgram, Hungary) emitting mainly in the UV-A range. The light was focused by an optical lens on the quartz cuvette containing the sample. The concentration of $\mathrm{MB}$ and IBR was measured by spectrophotometry and by HPLC, respectively. The presence of polymer did not affect the spectrophotometric determination. The concentration of MB and IBR solutions was set to 20 and $50 \mu \mathrm{M}$, respectively before irradiation.

The half-life time was calculated postulating first order rate kinetics. Representing the concentration of MB or IBR in natural logarithmic scale as a function of time linear relationships were obtained proving the first order kinetics of degradation. The regression coefficients were in the range of $0.98-1.00$. Three parallel measurements were evaluated.

\section{Determination of methylene blue concentration}

The concentration of the dye was measured by spectrophotometry using Agilent 8453 spectrophotometer at $\lambda=664 \mathrm{~nm}$ using $750 \mathrm{~nm}$ as reference.

\section{Determination of ibuprofen concentration by HPLC}

An Agilent 1100 HPLC system equipped with a diode array detector $(254 \mathrm{~nm})$ was used with a Waters ODS C18 $(250 \mathrm{~mm} \times 4.6 \mathrm{~mm}, 5 \mu \mathrm{m})$ analytical column and elution with $45 \%$ acetonitrile and $0.05 \%$ formic acid in water at a flow rate of $1.0 \mathrm{~mL} / \mathrm{min}$. The column temperature was set to $40{ }^{\circ} \mathrm{C}$. The samples were diluted with $50 \%$ acetonitrile in $1: 1$ ratio before injecting $5 \mu \mathrm{L}$.

\section{Characterization of the molecular weight distribu- tion by HPLC}

The same equipment was used with refractive index detector and TSK gel G2000SW silicagel based column (TosoHaas) $(7.5 \times 300 \mathrm{~mm}, 10 \mu \mathrm{m}$ (molecular weight ranges: 1-30 kDa)), and guard column $(7.5 \times 75 \mathrm{~mm})$ for size exclusion chromatography of CMBCD-P. The mobile phase (water, $\mathrm{pH}$ adjusted to 2.7 with cc. $\mathrm{H}_{3} \mathrm{PO}_{4}$ ) was eluted with $1 \mathrm{~mL} / \mathrm{min}$. The temperature of the column and of the RI detector was adjusted to $30^{\circ} \mathrm{C}$ and $40{ }^{\circ} \mathrm{C}$, respectively. The samples containing $10 \mathrm{mg} / \mathrm{mL}$ CMBCD-P were diluted to $5 \mathrm{mg} / \mathrm{mL}$ with the mobile phase and $20 \mu \mathrm{L}$ was injected.

\section{Acknowledgements}

The authors thank to Katalin Csabai for the size exclusion chromatography of the polymer.

\section{References}

1. Matero-Sagasta, J.; Raschid-sally, L.; Thebo, A. Global Wastewater and Sludge Production, Treatment and Use. In Wastewater. Economic Asset in an Urbanizing World; Drechsel, P.; Qadir, M.; Wicheins, D., Eds.; Springer: Berlin, 2015; pp 15-38. 
2. EIB Water and Waste water management. http://www.eib.org/projects/sectors/water-and-waste-water-manageme nt/index.htm (accessed July 27, 2016).

3. Petrie, B.; Barden, R.; Kasprzyk-Hordern, B. Water Res. 2015, 72, 3-27. doi:10.1016/j.watres.2014.08.053

4. US Environmental Protection Agency. https://www.epa.gov/wqc/contaminants-emerging-concern-including-ph armaceuticals-and-personal-care-products (accessed June 20, 2016).

5. WHO Information sheet.

http://www.who.int/water_sanitation_health/emergencies/en/ (accessed June 20, 2016).

6. Nagy, Z. M.; Molnár, M.; Fekete-Kertész, I.; Molnár-Perl, I.; Fenyvesi, É.; Gruiz, K. Sci. Total Environ. 2014, 485-486, 711-719. doi:10.1016/j.scitotenv.2014.04.003

7. Jurecska, L.; Dobosy, P.; Barkács, K.; Fenyvesi, É.; Záray, G. J. Pharm. Biomed. Anal. 2014, 98, 90-93. doi:10.1016/j.jpba.2014.05.007

8. Szejtli, J.; Osa, T., Eds. Cyclodextrins; Comprehensive Supramolecular Chemistry, Vol. 3; Pergamon: Oxford, UK, 1996.

9. Fenyvesi, É.; Molnár, M.; Leitgib, L.; Gruiz, K. Land Contam. Reclam. 2009, 17, 585-597.

10. Villaverde, J.; Morillo, E. Remediation of contaminated soils and long-term risk assessment of organic residues by using cyclodextrins. In Cyclodextrins in Pharmaceutics, Cosmetics, and Biomedicine; Bilensoy, E., Ed.; John Wiley \& Sons, Inc.: Hoboken, N. J., 2011; pp 199-233.

11. Crini, G.; Morcellet, M. J. Sep. Sci. 2002, 25, 789-813. doi:10.1002/1615-9314(20020901)25:13<789::AID-JSSC789>3.0.CO;2 $-J$

12. Gruiz, K.; Molnár, M.; Fenyvesi, É.; Hajdu, C.; Atkári, A.; Barkács, K. J. Inclusion Phenom. Macrocyclic Chem. 2011, 70, 299-306. doi:10.1007/s10847-010-9909-y

13. Sawicki, R.; Mercier, L. Environ. Sci. Technol. 2006, 40, 1978-1983. doi:10.1021/es051441r

14. Ertas, Y.; Celebioglu, A.; Uyar, T. In Abstract Book of 18th International Cyclodextrin Symposium, Gainesville, Florida, May 19-21, 2016; p 91.

15. Chen, C.-Y.; Chen, C.-C.; Chung, C.-Y. Bioresour. Technol. 2007, 98, 2578-2583. doi:10.1016/j.biortech.2006.09.009

16. Forouharshad, M.; Putti, M.; Basso, A.; Prato, M.; Monticelli, O. ACS Sustainable Chem. Eng. 2015, 3, 2917-2924. doi:10.1021/acssuschemeng.5b00892

17. Alsbaiee, A.; Smith, B. J.; Xiao, L.; Ling, Y.; Helbling, D. E.; Dichtel, W. R. Nature 2016, 529, 190-194. doi:10.1038/nature16185

18. Furuta, T.; Ikefuji, S.; Tokunaga, K.; Neoh, T. L.; Yoshii, H. J. Inclusion Phenom. Macrocyclic Chem. 2007, 57, 21-27. doi:10.1007/s10847-006-9168-0

19. Cai, X.; Liu, Q.; Xia, C.; Shan, D.; Du, J.; Chen, J. Environ. Sci. Technol. 2015, 49, 9264-9272. doi:10.1021/acs.est.5b01734

20. Gaya, U. I.; Abdullah, A. H. J. Photochem. Photobiol., C: Photochem. Rev. 2008, 9, 1-12. doi:10.1016/j.jphotochemrev.2007.12.003

21. Chan, S. H. S.; Wu, T. Y.; Juan, J. C.; Teh, C. Y. J. Chem. Technol. Biotechnol. 2011, 86, 1130-1158. doi:10.1002/jctb.2636

22. Chakrabarti, S.; Dutta, B. K. J. Hazard. Mater. 2004, 112, 269-278. doi:10.1016/j.jhazmat.2004.05.013

23. Pitchaimuthu, S.; Rajalakshmi, S.; Kannan, N.; Velusamy, $P$. Appl. Water Sci. 2015, 5, 201-208. doi:10.1007/s13201-014-0181-y
24. Wang, G.; Wang, X.; Yu, R.; Deng, N. Fresenius Environ. Bull. 2008, 17, 1054-1060.

25. Wang, G.; Wu, F.; Zhang, X.; Luo, M.; Deng, N. J. Chem. Technol. Biotechnol. 2006, 81, 805-811. doi:10.1002/jctb.1513

26. Kamiya, M.; Nakamura, K.; Sasaki, C. Chemosphere 1994, 28, 1961-1966. doi:10.1016/0045-6535(94)90146-5

27. Glass, B. D.; Brown, M. E.; Daya, S.; Worthington, M. S.; Drummond, P.; Antunes, E.; Lebete, M.; Anoopkumar-Dukie, S.; Maharaj, D. Int. J. Photoenergy 2001, 3, 205-211. doi:10.1155/S1110662X01000277

28. Sortino, S.; Giuffrida, S.; De Guidi, G.; Chillemi, R.; Petralia, S.; Marconi, G.; Condorelli, G.; Sciuto, S. Photochem. Photobiol. 2001, 73, 6-13. doi:10.1562/0031-8655(2001)0730006TPOFAI2.0.CO2

29. Shen, J.; Li, N.; Ye, M. J. Alloys Compd. 2013, 580, 239-244. doi:10.1016/j.jallcom.2013.05.090

30. Sharavath, V.; Sarkar, S.; Gandla, D.; Ghosh, S. Electrochim. Acta 2016, 210, 385-394. doi:10.1016/j.electacta.2016.05.177

31. Chalasani, R.; Vasudevan, S. ACS Nano 2013, 7, 4093-4104. doi:10.1021/nn400287k

32. Hashimoto, K.; Irie, H.; Fujishima, A. Jpn. J. Appl. Phys. 2005, 44, 8269-8285. doi:10.1143/JJAP.44.8269

33. Willner, I.; Eichen, Y. J. Am. Chem. Soc. 1987, 109, 6862-6863. doi:10.1021/ja00256a056

34. Zhang, X.; Wu, F.; Deng, N. J. Hazard. Mater. 2011, 185, 117-123. doi:10.1016/j.jhazmat.2010.09.005

35. Willner, I.; Eichen, Y.; Willner, B. Res. Chem. Intermed. 1994, 20 , 681-700. doi:10.1163/156856794X00487

36. Lannoy, A.; Kania, N.; Bleta, R.; Fourmentin, S.; Machut-Binkowski, C.; Monflier, E.; Ponchel, A. J. Colloid Interface Sci. 2016, 461, 317-325. doi:10.1016/j.jcis.2015.09.022

37. Fenyvesi, E. Cyclodextrin News 2014, 28, 1-9.

38. Subramanian, R.; Sakthivel, P.; Nagarathinam, K.; Ponnusamy, V. Appl. Water Sci. 2014, 1-14.

39. Gao, Z.; Mi, Y.; Gao, L. Titania photocatalyst bonded with carboxymethyl-beta-cyclodextrin. Chin. Pat. 1698961, Nov 23, 2005. Chem. Abstr. 2005, 145, 302705.

40. Evonic Industries: AEROXIDE ${ }^{\circledR}$, AERODISP $^{\circledR}$ and AEROPERL ${ }^{\circledR}$ Titanium Dioxide as Photocatalyst. Technical Information 1243. http://www.aerosil.com/sites/lists/RE/DocumentsSI/TI-1243-Titanium-Di oxide-as-Photocatalyst-EN.pdf (accessed July 27, 2016).

41. Aerodisp ${ }^{\circledR}$ product information. https://www.aerosil.com/www2/uploads/productfinder/VP-Disp-W-2730X-EN.pdf (accessed July 27, 2016).

42. He, Y.; Sutton, N. B.; Rijnaarts, H. H. H.; Langenhoff, A. A. M. Appl. Catal., B: Environ. 2016, 182, 132-141. doi:10.1016/j.apcatb.2015.09.015

43. Feng, W.; Nansheng, D. Chemosphere 2000, 41, 1137-1147. doi:10.1016/S0045-6535(00)00024-2

44. Guillard, C.; Puzenat, E.; Lachheb, H.; Houas, A.; Herrmann, J.-M. Int. J. Photoenergy 2005, 7, 1-9. doi:10.1155/S1110662X05000012

45. Doll, T. E.; Frimmel, F. H. Water Res. 2005, 39, 403-411. doi:10.1016/j.watres.2004.09.016

46. Attarchi, N.; Montazer, M.; Toliyat, T. Appl. Catal., A 2013, 467, 107-116. doi:10.1016/j.apcata.2013.07.018

47. Reijenga, J. C.; Ingelse, B. A.; Everaerts, F. M. J. Chromatogr. A 1997, 792, 371-378. doi:10.1016/S0021-9673(97)00644-4

48. Mura, P.; Manderioli, A.; Bettinetti, G. P.; Bramanti, G. 1st World Meeting on Pharmaceutics, Biopharmaceutics and Pharmaceutical Technology, Budapest, Hungary, May 9-11, 1995; pp 595-596. 
49. Hirai, H.; Toshima, N.; Uenoyama, S. Bull. Chem. Soc. Jpn. 1985, 58, 1156-1164. doi:10.1246/bcsj.58.1156

50. Scott, J.; Tidball, A.; Uitvlugt, J. M.; Lucia, M.; Griend, D. A. V.; Douglas, A.; Louters, L. L. Biochimie 2007, 91, 271-276. doi:10.1016/j.biochi.2008.10.003

51. Liu, W.; Zhang, Y.; Zhao, B. J. Chin. Chem. Soc. 2012, 59, 1155-1158. doi:10.1002/jccs.201200071

52. Malanga, M.; Bálint, M.; Puskás, I.; Tuza, K.; Sohajda, S.; Jicsinszky, L.; Szente, L.; Fenyvesi, É. Beilstein J. Org. Chem. 2014, 10, 3007-3018. doi:10.3762/bjoc.10.319

53. Puskás, I.; Szemjonov, A.; Fenyvesi, E.; Malanga, M.; Szente, L. Carbohydr. Polym. 2013, 94, 124-128. doi:10.1016/j.carbpol.2013.01.025

54. Budapest Potable Water Analysis (in Hungarian). http://www.egyutteuropaert.eu/wp-content/uploads/2013/01/Budapesti_ ivovizvizsgalat.pdf (accessed Dec 7, 2016).

\section{License and Terms}

This is an Open Access article under the terms of the Creative Commons Attribution License

(http://creativecommons.org/licenses/by/4.0), which permits unrestricted use, distribution, and reproduction in any medium, provided the original work is properly cited.

The license is subject to the Beilstein Journal of Organic Chemistry terms and conditions:

(http://www.beilstein-journals.org/bjoc)

The definitive version of this article is the electronic one which can be found at: doi:10.3762/bjoc. 12.286 